\title{
COSMO-SkyMed potential to detect and monitor Mediterranean maquis fires and regrowth: a pilot study in Capo Figari, Sardinia, Italy
}

\author{
Gaia Vaglio Laurin ${ }^{(1-2)}$, \\ Ruggero Avezzano (3), \\ Valentina Bacciu ${ }^{(2)}$, \\ Fabio Del Frate ${ }^{(3)}$, \\ Dario Papale ${ }^{(1)}$, \\ Maria Virelli ${ }^{(4)}$
}

\begin{abstract}
Mediterranean maquis is a complex and widespread ecosystem in the region, intrinsically prone to fire. Many species have developed specific adaptation traits to cope with fire, ensuring resistance and resilience. Due to the recent changes in socio-economy and land uses, fires are more and more frequent in the urban-rural fringe and in the coastlines, both now densely populated. The detection of fires and the monitoring of vegetation regrowth is thus of primary interest for local management and for understanding the ecosystem dynamics and processes, also in the light of the recurrent droughts induced by climate change. Among the main objectives of the COSMO-SkyMed radar constellation mission there is the monitoring of environmental hazards; the very high revisiting time of this mission is optimal for post-hazard response activities. However, very few studies exploited such data for fire and vegetation monitoring. In this research, Cosmo-SkyMed is used in a Mediterranean protected area covered by maquis to detect the burnt area extension and to conduct a mid-term assessment of vegetation regrowth. The positive results obtained in this research highlight the importance of the very high-resolution continuous acquisitions and the multi-polarization information provided by COSMO-SkyMed for monitoring fire impacts on vegetation.
\end{abstract}

\section{Keywords: Cosmo-SkyMed, Maquis, Fire, Mediterranean Vegetation}

\section{Introduction}

The Mediterranean maquis is mostly char acterized by evergreen woody shrubs ( $0.5-$ $5 \mathrm{~m}$ tall) with sclerophyllous leaves; often isolated trees or small trees patches are present, as well as gaps with bare soil and rocks. Differences in aspect, slope and soil depth can generate large variation in species presence, vegetation cover and height. In the Mediterranean climate, rainfalls are mainly concentrated in fall and winter. It is during the very dry summer that most of the fire events take place, some of which can be extremely severe and very dangerous also for the neighboring population. The Mediterranean maquis co-evolved with disturbance caused by hu- man activities, including fire which can promote regeneration, and after which rapid regrowth $(\sim 5-10$ years) usually take place (Ricotta et al. 1998, Shoshany 2000). However, strong anthropic pressure and fragmentation of the landscape, together with increased temperatures and prolonged droughts as a result of climate change, have increased fire risk and events severity (Ruffault \& Mouillot 2017). Thus any destructive event, such as natural or humaninduced fire, needs to be carefully monitored for the caused damages and the recovery response (Corona et al. 2008).

Remote sensing has a fundamental role in the provision of fire-related information and different optical and microwave sen-
(1) Department for Innovation in Biological, Agro-Food and Forest Systems (DIBAF), University of Tuscia, I-01100 Viterbo (Italy); (2) Fondazione CMCC (Euro-Mediterranean Center on Climate Change), Division on Impacts on Agriculture, Forests and Ecosystem Services, I-07100 Sassari and I-01100 Viterbo (Italy); (3) Department of Civil Engineering and Computer Sciences (DICII), University of Rome Tor Vergata, I-00100 Rome (Italy); (4) Italian Space Agency, I-00100 Rome (Italy)

@ Gaia Vaglio Laurin (gaia.vagliolaurin@cmcc.it)

Received: Sep 03, 2017 - Accepted: Mar 05, 2018

Citation: Vaglio Laurin G, Avezzano R, Bacciu V, Del Frate F, Papale D, Virelli M (2018). COSMO-SkyMed potential to detect and monitor Mediterranean maquis fires and regrowth: a pilot study in Capo Figari, Sardinia, Italy. iForest 11: 389-395. - doi: 10.3832/ifor2623-011 [online 2018-05-15]

Communicated by: Davide Ascoli sors are used in hazard monitoring, with a key factor being the satellite revisiting time to minimize the time lag between pre- and post-event data and to conduct efficient follow up (Joyce et al. 2009, Karteris 1996). For vegetation monitoring, usually image acquisition is conducted during a pre-fire phase to characterize the area (e.g., classification of vegetation types, or fuel load prediction), a short-term post-fire phase to record the extent and severity of fire, and a $\mathrm{mid} /$ long-term post-fire phase to monitor the regeneration of vegetation (Gitas et al. 2012).

Post-fire assessments have been conducted prevalently using optical data; however some studies also report the use of Synthetic Aperture Radar (SAR) data, or combination of optical and SAR (Bernhard et al. 2011, 2012, Diaz-Delgado et al. 2003, Gimeno \& San-Miguel-Ayanz 2004, Lentile et al. 2006, Mari et al. 2012, Polychronaki et al. 2013, Ranson et al. 2002, Tanase et al. 2010a, 2010b, 2010c, 2014, Van Wagtendonk et al. 2004). Possibly, the wider use of optical data is related to their broader diffusion in previous decades and their easier processing with respect to SAR, though in recent years both data types are equally available and supported by image processing software. The larger use of optical data also allowed to establish strong relationships, such as the linear relation between the Composite Burnt Index (Key \& Benson 2004), designed to ecologically define burn severity, and optical-derived indices such as the differential Normalized Burn Ratio 
( $\triangle$ NBR - Kasischke et al. 2007).

Mid/long-term assessments to monitor vegetation regrowth have been extensively reviewed by Gitas et al. (2012), who concluded that medium resolution optical satellites have been mostly used, due to the need of time-series. For regrowth monitoring, the use of a vegetation index derived from optical data has been proposed by Bastos et al. (2011). Using higher resolution satellite optical data in synergy (Landsat and WorldView-2), Chu et al. (2016) were able to detect post-fire regeneration in a larch forest, developing a new Forest Recovery Index. Similarly, Arnett et al. (2015) showed that RapidEye optical image was able to differentiate various level of canopy damage due to fire better than Landsat, thanks to its higher spatial resolution. However, cloud-cover presence often hampers the possibility to collect dense time series optical images over forested regions.

Although SAR data are known to have different potential for ecological applications (Kasischke et al. 2007), its use in fire monitoring is less frequent. These data can be used to estimate not only the burnt severity but also the fuel load (Saatchi et al. 2007). In the case of fire monitoring, SAR insensitiveness to cloud cover and haze is definitively an advantage with respect to optical data, which often are unavailable due to smoke and cloud presence during and after fire occurrence. Changes of the vegetation volumetric structure can be also detected by SAR, thanks to the sensitivity of microwaves to woody structure presence and water content. SAR time-series have been used by Minchella et al. (2009) and Tanase et al. (2011) for monitoring the vegetation recovery in Mediterranean and boreal ecosystems. While different frequencies can be used according to vegetation type and size of branches, the incidence angle is an important parameter to take into account, as steeper angles increase the contribution from soil while at large angles the effect of volumetric scattering is dominant (Attema \& Ulaby 1978). In all cases, to avoid seasonal effects in time-series analysis of vegetation regrowth patterns, the use of unburned control points in proximity of the burnt area is suggested (Diaz-Delgado \& Pons 2001).

COSMO-SkyMed (CSK) is a constellation composed of four satellites equipped with Synthetic Aperture Radar operating at Xband. The first satellite has been launched by the Italian Space Agency (ASI) on June 2007 , and the full constellation is operational since mid-2010. CSK is designed to provide products/services for environmental monitoring and surveillance and for military purposes. CSK has the capability of acquiring a large amount of daily images; it has all weather and day/night acquisition capabilities, and very short interval between the acceptance of the user request and the release of the remote sensing product (Covello et al. 2010). CSK has high spatial and radiometric resolution, with different acquisition modes, including CSK Stripmap products, that are the base of the Map Italy archive, and provide very frequent imagery over the whole Italian territory, with optimal potential for hazard events monitoring.

This research explores for the first time the use of CSK data for post-fire monitoring of Mediterranean vegetation. Specifically, the Map Italy archive has been used for the short-term assessment, while a specific acquisition campaign for mid-term assessment has been realized over the study site, a protected areas located in coastal Sardinia, Italy, covered by a large fire in 2013. The study is based on the hypothesis that CSK data can efficiently map burnt area and monitor the regrowth of maquis vegetation at least at an initial phase of recovery, thanks to the exploitation of dense time-series, of different polarizations, and to the acquisition of data at different inci- dence angles. To summarize, the objective of the present research is to test the suitability of CSK SAR data for vegetation burnt areas detection and regrowth monitoring, comparing the results with those obtained with commonly used optical freely available data.

\section{Methods}

The study includes a short-term and a mid-term assessment phase. The shortterm assessment is based on the use of two CSK Map Italy SAR images, collected soon before and after the fire event, in order to map the burnt area extent. SAR results were compared in accuracy with those obtained using Landsat 8 optical data, and both were validated using the fire perimeter data collected by GPS in the field by the Sardinian Forest Service. The mid-term assessment was based on the use of long CSK time series to monitor the amount of vegetation regrowth after the fire damage. The results were evaluated using vegetation field data collected in specific field surveys.

\section{Study area and ground data}

The Capo Figari study area (Fig. 1) is a Site of Community Importance (SIC) listed in the European Commission Habitats Directive; this peninsula is located in northeastern Sardinia region $\left(40^{\circ} 59^{\prime} \mathrm{N}, 09^{\circ} 38^{\prime} \mathrm{E}\right)$ and on June $25^{\text {th }} 2013$ was impacted by a large fire (>100 ha), according to the classification of the European Forest Fire Information System (San-Miguel-Ayanz et al. 2012). The area is characterized by heterogeneous morphology; elevation ranges between 0 and $340 \mathrm{~m}$, with slopes up to $80^{\circ}$. The climate in the region is Mediterranean, with monthly average precipitation in the range $2-41 \mathrm{~mm}$ and monthly average temperatures in the range $10-25{ }^{\circ} \mathrm{C}$. The dominant vegetation is composed by Mediterranean shrubs, adapted to the very dry summer months, such as Erica arborea, Gi-
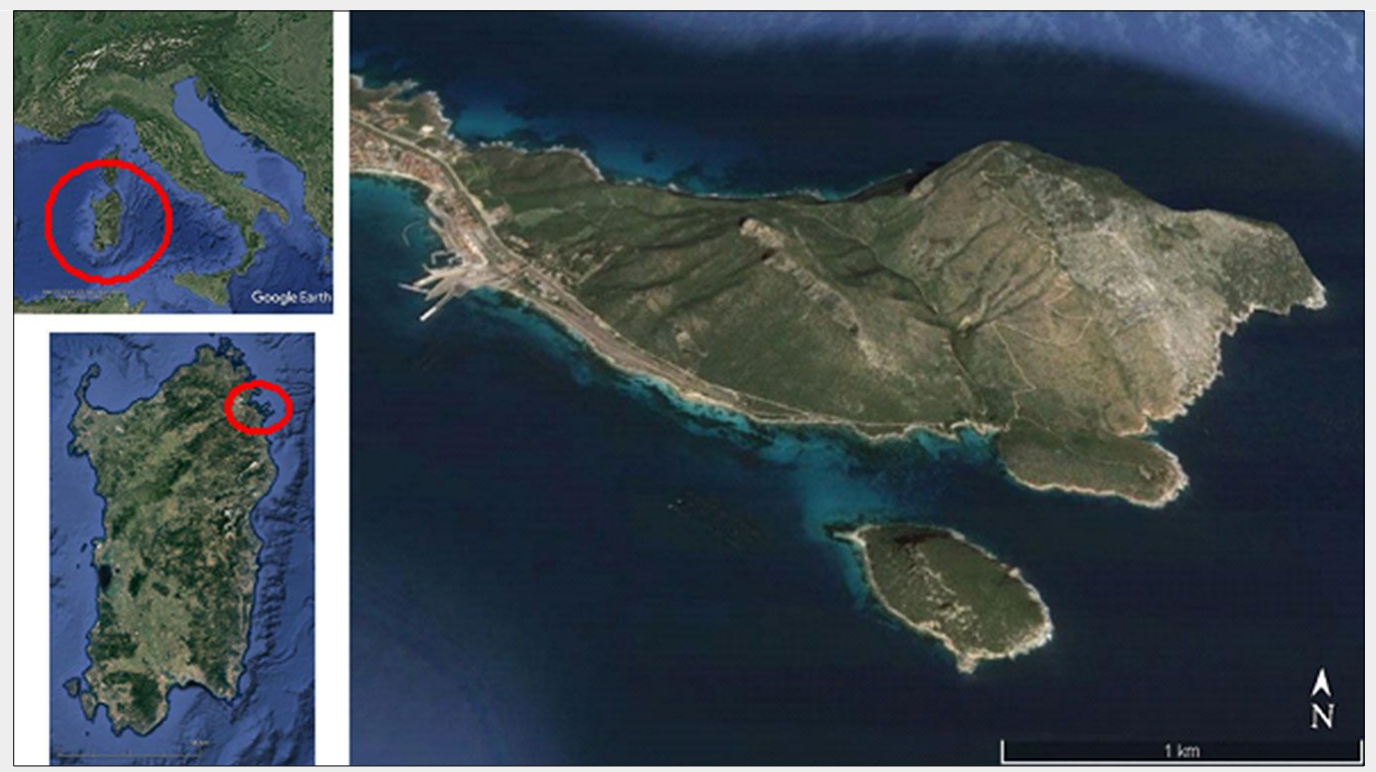

Fig. 1 - Upper left: Sardinia island in Italy (in the red circle). Lower left: the location of the study area in Sardinia (in the red oval). Larger image: the Capo Figari study area. 
nestra spp., Euphorbia dendroides, Pistacia lentiscus, and Juniperus spp.; Cistus spp. is abundant as a result of regeneration from past fire events. The extent of the burnt area was mapped by the Sardinian Forest Service (CFVA) on October $4^{\text {th }} 2013$, by means of a Global Positioning System (GPS) field survey: the fire affected 195.22 ha, of which 190 ha composed by Mediterranean maquis and 5.22 by uncultivated areas. Considering that in this coastal area slope and aspect have a strong effect on the vegetation type and development, the study site was stratified in sub-areas according to ancillary information, including: Corine Land Cover 2006 (CLC2006), a 2006 Ikonos very high resolution optical image, 1 $\mathrm{m}$ spatial resolution 2006 orthophotos, and a $10 \mathrm{~m}$ spatial resolution Digital Elevation Model (DEM).

On the $4^{\text {th }}-5^{\text {th }}$ April and $16^{\text {th }}$ July 2014 two field campaigns were conducted to collect maquis parameters. Ten transect of $15 \mathrm{~m}$ each were randomly located in each of the maquis sub-areas previously identified. Vegetation cover data was collected using the point intercept method at every 0.50 $\mathrm{m}$, where a pole was used to identify the height and species of any plant hitting the pole. Percentage cover was calculated as the number of hits for each species or ground cover class divided by the total number of points per transect. Plant height was also recorded by measuring the vertical distance from the soil surface to the top of the branches.

\section{Remote sensing data and analyses}

SAR data for short-term assessment are two scenes from CSK Map Italy archive: a pre-fire scene acquired on $18^{\text {th }}$ of June 2013 and a post-fire one dated $4^{\text {th }}$ of July 2013. Single Look Slant Range scenes were acquired in Hi-Image mode, with 3 meters ground resolution, $\mathrm{HH}$ single polarization and $24^{\circ}$ incidence angle. Intensity images were co-registered, calibrated and orthorectified using a $10 \mathrm{~m}$ DEM, with final spatial resolution kept equal to $3 \mathrm{~m}$. Backscattering coefficient was normalized following Ulander (1996) and a refined Lee filter with $9 \times 9$ pixel window was used for speckle reduction. A normalised backscattering change index $(\mathrm{BCl})$ was computed as the normalized difference in gamma naught between post-event $\left(\gamma_{\text {post }}^{0}\right)$ and preevent $\left(\gamma_{\text {pre }}^{0}\right)$ scenes (eqn. 1):

$$
B C I=\frac{\gamma_{p o s t}^{0}-\gamma_{p r e}^{0}}{\gamma_{p o s t}^{0}+\gamma_{p r e}^{0}}
$$

Negative $\mathrm{BCl}$ values were excluded from the analysis, considering that at $\mathrm{HH}$ polarization and $24^{\circ}$ incidence angle an increase in backscattering is caused by the increased contribution of soil after fire event. A threshold was arbitrary selected to distinguish burnt from non-burnt areas; a morphological filter based on a $5 \times 5$ kernel was used to improve burnt area delineation in SAR images.
Optical data for short-term assessment are two Landsat 8 L1T images, acquired on $23^{\text {rd }}$ of June and $2^{\text {nd }}$ of July. Images were atmospherically corrected using the ATCOR2 package (Richter \& Schläpfer 2015). The normalized burnt ratio index (NBR) was computed for each image as the normalized difference between the reflectance at $2.2 \mu \mathrm{m}$ (Short Wave Infra-Red - SWIR) and $0.86 \mu \mathrm{m}$ (Near Infra-Red, NIR - eqn. 2):

$$
N B R=\frac{\rho N I R-\rho S W I R}{\rho N I R+\rho S W N I R}
$$

The $\triangle N B R$, also considered as indicator of fire severity according to Cocke et al. (2005), was calculated as the difference between the index values in pre- and postevent images. The averaged $\triangle N B R$ value for the study site was used as threshold to delineate burnt area in optical imagery.

For the mid-term assessment, considering the steep slopes in Capo Figari, CSK acquisitions were planned at incidence angles included in the $40^{\circ}-50^{\circ}$ range, in order to reduce layover and shadowing distortion effects, and realized between December 2013 and August 2014. CSK constellation can provide an average of 6 scenes in a 16day orbital cycle, with 3 ascending and 3 descending acquisitions. StripMap Single Look Complex Ping-Pong HH-HV scenes, at 15 meters ground resolution, were acquired at $43^{\circ}$ in descending pass (43D, 47 total scenes) and $49^{\circ}$ in ascending pass (49A, 39 total scenes).

Intensity images were co-registered, calibrated and orthorectified using a $10 \mathrm{~m}$ DEM. Backscattering coefficient was normalized following Ulander (1996) and a refined Lee filter with $5 \times 5$ pixel window was used for speckle reduction. The combination of ascending and descending acquisitions allowed the exploitation of multi-angle views, as the terrain slope modifies the actual local incidence angle (LIA).

Backscattering values at $\mathrm{HH}, \mathrm{HV}$ and $\mathrm{HV}$ / $\mathrm{HH}$ polarization ratio were analyzed as function of $5^{\circ}$ increasing LIA. Values around each $5^{\circ}$ step were grouped and averaged, following the approach proposed by Tanase et al. (2010b).

Linear trends in backscattering time-series at each $5^{\circ}$ step have been computed for each strata. The slopes obtained from linear time-series trends were used to derive a regression model for vegetation parameters prediction.

\section{Results}

In Capo Figari few areas are characterized by very steep zones $\left(>35^{\circ}\right)$, where bare soil and rocks are dominant with almost absence of vegetation; thus areas having a slope $>35^{\circ}$ were excluded from the analysis. Three slopes classes were considered: No_Slope $\left(<10^{\circ}\right)$, Low_Slope $\left(10^{\circ}-20^{\circ}\right)$, Medium Slope $\left(20^{\circ}-35^{\circ}\right)$. Three main vegetation types were present according to CLC2006: Mediterranean Maquis (M), Gariga (GA), and Sparse Vegetation (AR). The Mediterranean Maquis type was subdivided by visual interpretation of orthophotos and Ikonos imagery in Dense Maquis (MD), Intermediate Maquis (MI) and Sparse Maquis (MS). The Sparse Vegetation type was further subdivided according to aspect into: eastward Sparse Vegetation (AR1) and westward Sparse Vegetation (AR2). An area not affected by fire was finally delineated and used as control: Unburnt Maquis (UM). Thus, the stratification of the study area based on interpretation of ancillary information resulted in the identification of 7 homogeneous sub-areas, as summarized in Tab. 1. The three maquis classes (MD, MI, MS) were sampled with 10 transects per each maquis type in April and 7 transects in July field campaigns.

Ground data analysis indicate that the percentage of vegetation cover did not show any significant increase between April and July (t-test, $p>0.05$ ), during which regrowth started. MD and MS subareas showed similar composition, with high vegetation (50-60\%) and low bare soil (11-15\%) values, while MI sub-area showed higher bare soil (39-46\%) coverage. Vegetation height significantly increased in all the sub-area ( $t$-test, $p<0.05$ ): in MD the average increase from April to July resulted equal to $75 \%$ (from 17.54 to $31.44 \mathrm{~cm}$ ), in $\mathrm{MI}$ equal to $70 \%$ (from 15.44 to $26.81 \mathrm{~cm}$ ), in MS equal to $98 \%$ (from 17.25 to $35.05 \mathrm{~cm}$ ).

\section{Short-term assessment}

For the short-term assessment, the burnt areas identified by means of a threshold applied to $\mathrm{BCl}$ derived from CSK scene and the averaged $\triangle N B R$ derived from Landsat 8 images were compared to the area detected by the GPS survey of the Sardinian Forest Service (Fig. 2). Results showed that optical and SAR correctly identified the $78 \%$ of the ground delineated burnt area (169 ha), while Landsat 8 correctly identified the

Tab. 1 - Homogeneous sub-areas characteristics.

\begin{tabular}{lllll}
\hline Class & $\begin{array}{l}\text { Vegetation } \\
\text { type }\end{array}$ & $\begin{array}{l}\text { Vegetation } \\
\text { density }\end{array}$ & Aspect & Slope \\
\hline MD & Mediterranean Maquis & Dense & North & Low/Medium \\
MI & Mediterranean Maquis & Intermediate & West & Medium \\
MS & Mediterranean Maquis & Sparse & South/East & Flat/Low \\
GA & Gariga & Intermediate & East & Medium \\
AR1 & Sparse Vegetation & Sparse & West & Medium \\
AR2 & Sparse Vegetation & Sparse & East & Medium \\
UM & Mediterranean Maquis & Intermediate/Dense & West & Low/Medium \\
\hline
\end{tabular}




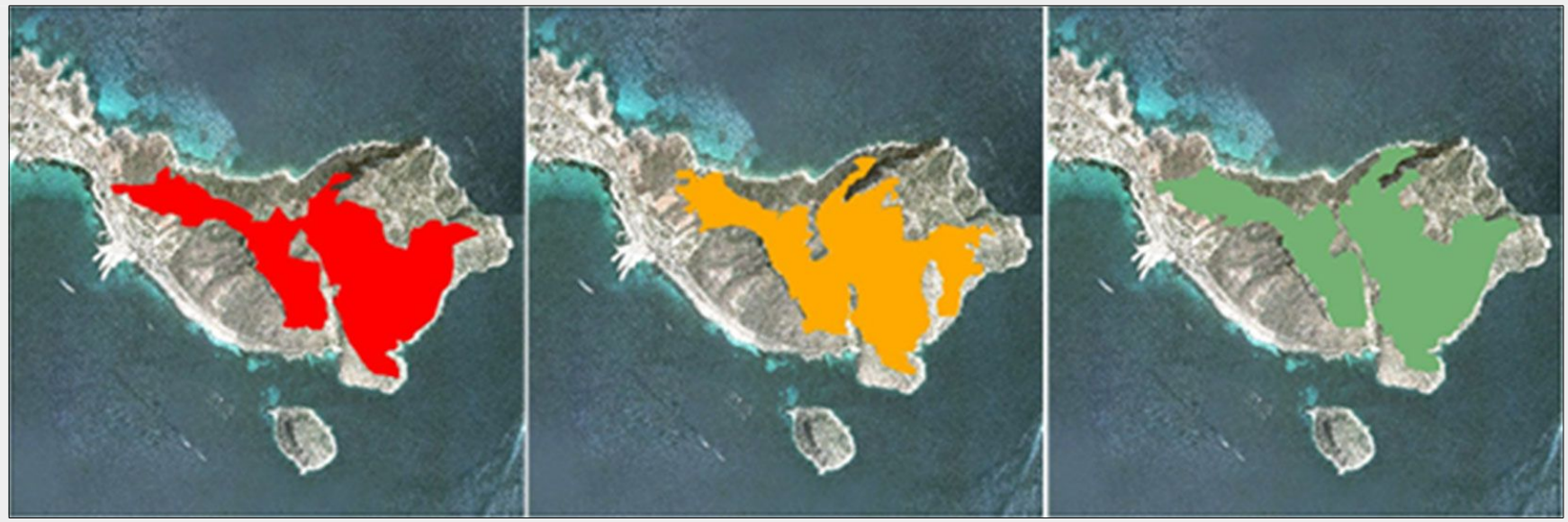

Fig. 2 - Comparison of burnt areas detected by GPS survey (red), SAR data (orange), and Landsat 8 (green).

Tab. 2 - Backscattering, $\mathrm{BCl}, \triangle \mathrm{NBR}$ and correlation values at increasing $5^{\circ} \mathrm{LIA}$ steps.

\begin{tabular}{llllllllll}
\hline Parameter & $\mathbf{1 0}^{\circ}$ & $\mathbf{1 5}^{\circ}$ & $\mathbf{2 0}^{\circ}$ & $\mathbf{2 5 ^ { \circ }}$ & $\mathbf{3 0 ^ { \circ }}$ & $\mathbf{3 5}^{\circ}$ & $\mathbf{4 0}^{\circ}$ & $\mathbf{4 5}^{\circ}$ & $\mathbf{5 0}^{\circ}$ \\
\hline $\mathrm{Y}^{0}$ pre $(\mathrm{dB})$ & -8 & -7.46 & -8.67 & -9.83 & -10.36 & -10.44 & -9.82 & -9.68 & -9.95 \\
$\mathrm{Y}^{0}$ post $(\mathrm{dB})$ & -5.65 & -4.98 & -6.57 & -8.05 & -9.21 & -8.9 & -7.96 & -7.78 & -8.13 \\
$\mathrm{BCl}$ & 0.27 & 0.25 & 0.23 & 0.19 & 0.12 & 0.17 & 0.21 & 0.22 & 0.21 \\
$\Delta$ NBR & 0.6 & 0.62 & 0.64 & 0.55 & 0.6 & 0.61 & 0.53 & 0.57 & 0.57 \\
Pearson $r$ & 0.31 & 0.47 & 0.62 & 0.47 & 0.34 & 0.38 & 0.34 & 0.38 & 0.43 \\
\hline
\end{tabular}

Tab. 3 - Backscattering, $\mathrm{BCl}, \triangle \mathrm{NBR}$ and correlation values per sub-area.

\begin{tabular}{lcccccc}
\hline Parameter & AR1 & AR2 & GA & MD & MI & MS \\
\hline$Y^{0}$ pre $(\mathrm{dB})$ & -5.1 & -5.42 & -8.87 & -11.95 & -10.49 & -11.7 \\
$Y^{0}$ post $(\mathrm{dB})$ & -4.38 & -3.68 & -5.71 & -9.82 & -8.39 & -10 \\
LIA & 32.4 & 15.42 & 18.23 & 31.6 & 42 & 24.8 \\
BCl & 0.08 & 0.19 & 0.29 & 0.22 & 0.23 & 0.18 \\
$\Delta$ NBR & 0.41 & 0.49 & 0.74 & 0.74 & 0.53 & 0.77 \\
Pearson $r$ & 0.08 & 0.41 & 0.34 & 0.55 & 0.32 & 0.33 \\
\hline
\end{tabular}
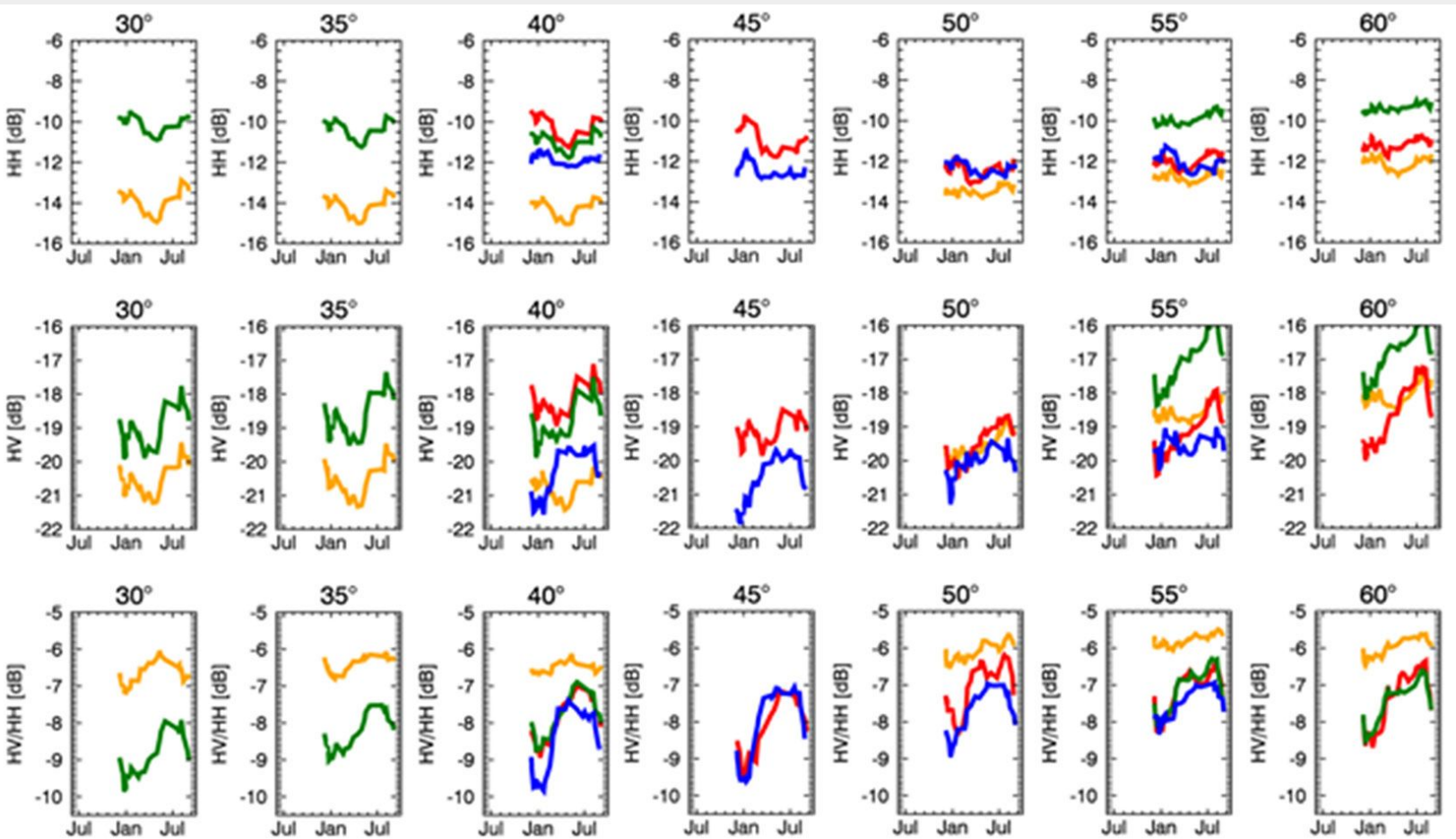

Fig. 3 - Time-Series plots for HH, HV and HV/HH per sub-area. (orange): UM (unburnt control); (red): MD (Dense Maquis); (green): MI (Intermediate Maquis); (blue): MS (Sparse Maquis). 
The backscattering, $\mathrm{BCl}, \triangle \mathrm{NBR}$, correlation and LIA values were extracted and averaged for each of the sub-areas previously identified (Tab. 3). AR1 and AR2 areas show higher backscattering values in both scenes, while the Maquis vegetated areas the lowest. The $\mathrm{BCl}$ shows a very low values in AR1 and AR2, which is thus not effectively recognized as burnt.

\section{Mid-term assessment}

For mid-term assessment, the three maquis sub-areas and the UM control area for which ground truth was available were considered. The regrowth dynamic was assessed at different $5^{\circ}$ LIA steps, but only steps for which at least $10 \%$ of the pixels were available were used in the analysis. This resulted in having the $40^{\circ}-60^{\circ}$ range for $\mathrm{MD}, 25^{\circ}-40^{\circ}$ and $55^{\circ}-60^{\circ}$ for $\mathrm{MI}, 40^{\circ}-55^{\circ}$ for MS, and $30^{\circ}-60^{\circ}$ for UM. The values for time series for each sub-area are plotted in Fig. 3 for $\mathrm{HH}, \mathrm{HV}$, and $\mathrm{HV} / \mathrm{HH}$ ratio, after applying a 3-acquisition moving average, with corresponding values for $\mathrm{HV} / \mathrm{HH}$ ratio shown in Tab. 4.

Linear trend were also computed to help the identification of best angles and polarizations for regrowth assessment, but only at $40^{\circ}$ and $55^{\circ}$ information is available for all the sub-areas. The $\mathrm{HV} / \mathrm{HH}$ ratio shows an increasing trend at different LIA steps in all sub-areas, with higher values for the UM case. Mean slopes for $\mathrm{HV} / \mathrm{HH}$ were equal to 0.85 for MD, 0.72 for MI, 0.84 for MS, and 0.28 for UM sub-area, with marked differences between burnt and control areas.

With limited ground truth, a preliminary test to evaluate the possibility of using slope values for prediction of vegetation regrowth was done, under the hypothesis that a change in vegetation height can influence the $\mathrm{HV} / \mathrm{HH}$ ratio at all the angles. The $\mathrm{HV} / \mathrm{HH}$ slopes at all incidence angles were averaged and this increase was applied to the April vegetation height measurement; results were compared with actual field data from July. The predicted height for MD in July was equal to $33.2 \mathrm{~cm}$, while the observed height to $31.4 \mathrm{~cm}$; for $\mathrm{MI}$ the predicted value was $27.2 \mathrm{~cm}$, while the observed one $26.8 \mathrm{~cm}$; for MS the predicted height was $32.5 \mathrm{~cm}$ and the observed $35.0 \mathrm{~cm}$. Overall, the differences resulted always below $8 \%$ of the observed values.

Finally, 10 scenes were selected from dates close to those of the July field measures, and the average slope values for $40^{\circ}$ and $55^{\circ}$ LIA for the three maquis sub-areas were computed. The results are illustrated in Fig. 4 in comparison with the observed field values. This $\mathrm{HV} / \mathrm{HH}$ ratio increase was also calculated for the whole study area to map the vegetation regrowth and is shown in Fig. 5, in which the burnt area according to GPS field measures is overlapped; the average change rate for the $\mathrm{HV} / \mathrm{HH}$ backscattering was $+0.8 \%$ day $^{-1}$ within the burnt area, while it resulted $+0.2 \%$ day $^{-1}$ outside the burnt area.

Tab. 4 - Backscattering HV/HH values per sub-area and LIA $5^{\circ}$ steps. When pixel number did not reach the $10 \%$ of those of the area, the values was not considered (indicated with " $n / a$ "). (UM): unburnt control; (MD); Dense Maquis; (MI): Intermediate Maquis; (MS): Sparse Maquis.

\begin{tabular}{llllllll}
\hline $\begin{array}{l}\mathrm{HV} / \mathrm{HH} \\
{[\mathrm{dB}]}\end{array}$ & $\mathbf{3} 0^{\circ}$ & $\mathbf{3} 5^{\circ}$ & $\mathbf{4 0}$ & $\mathbf{4 5 ^ { \circ }}$ & $\mathbf{5 0 ^ { \circ }}$ & $\mathbf{5 5 ^ { \circ }}$ & $\mathbf{6 0 ^ { \circ }}$ \\
\hline $\mathrm{MD}$ & $n / a$ & $n / a$ & -8.31 & -8.58 & -7.10 & -7.23 & -7.48 \\
$\mathrm{MI}$ & -9.40 & -8.71 & -8.28 & $n / a$ & $n / a$ & -7.17 & -7.51 \\
$\mathrm{MS}$ & $n / a$ & $n / a$ & -8.52 & -8.13 & -8.14 & -7.62 & $n / a$ \\
$\mathrm{UM}$ & -6.79 & -6.57 & -6.52 & $n / a$ & -6.10 & -5.79 & -5.98 \\
\hline
\end{tabular}

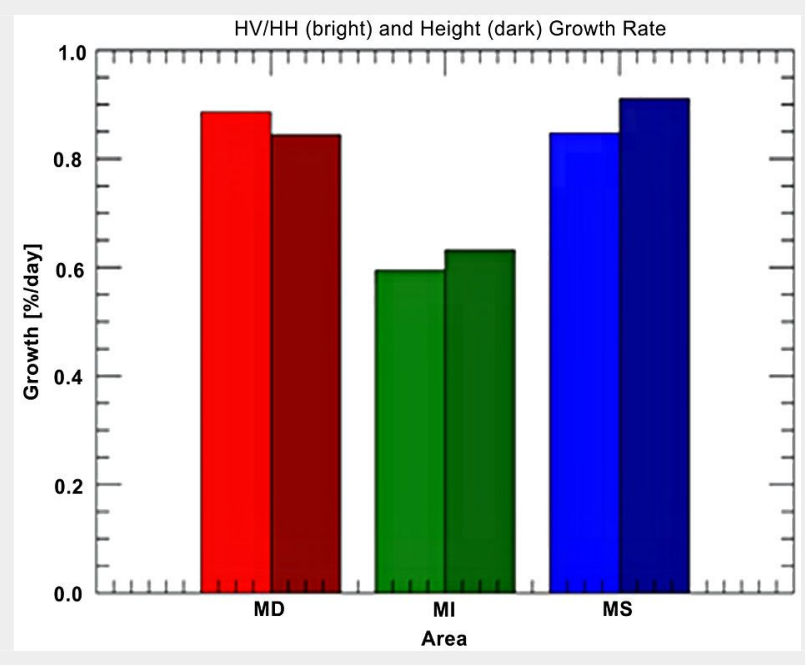

Fig. 4 - Averaged slope values calculated for 40 and 55 _ LIA in proximity of the field measurements. Bright bars represent $\mathrm{HV} / \mathrm{HH}$ derived slopes, dark bars represent the measured increases. (MD): Dense Maquis; (MI): Intermediate Maquis; (MS): Sparse Maquis.

\section{Discussion and conclusions}

Using CSK pre- and post-fire scenes, the burnt area has been accurately delineated. Results indicate that about $78 \%$ of the area defined as burnt by the CFVA ground survey has been correctly identified based on CSK data, with a result very similar to that obtained using Landsat 8; comparing the two data sources, CSK shows a larger commission error while Landsat 8 a larger omission error. This result is higher with respect to that from a previous comparison of SAR and optical data for forest fire mapping in the Mediterranean area, which showed that SAR correctly mapped $78 \%$ of the area identified by optical data as burnt (Berhard et al. 2011). The two sensors detect differ- ent features: while $\triangle N B R$ is primarily sensitive to vegetation chlorophyll content (Miller et al. 2009), BCI mostly responds to volumetric changes in the target. However, both responses are also influenced by water content in soil and vegetation. Kurum (2015) suggested that a SAR approach that combines pre- and postfire backscattering could be used to quantify the fire impacts, if the effects induced by geometry, weather, and other human activities are accounted for in the analysis. Tanase et al. (2015) conducted a comparison of fire severity as detected by Landsat or L-band SAR data for seven sites, concluding that the obtained accuracy is higher with optical data for high biomass forests, but comparable

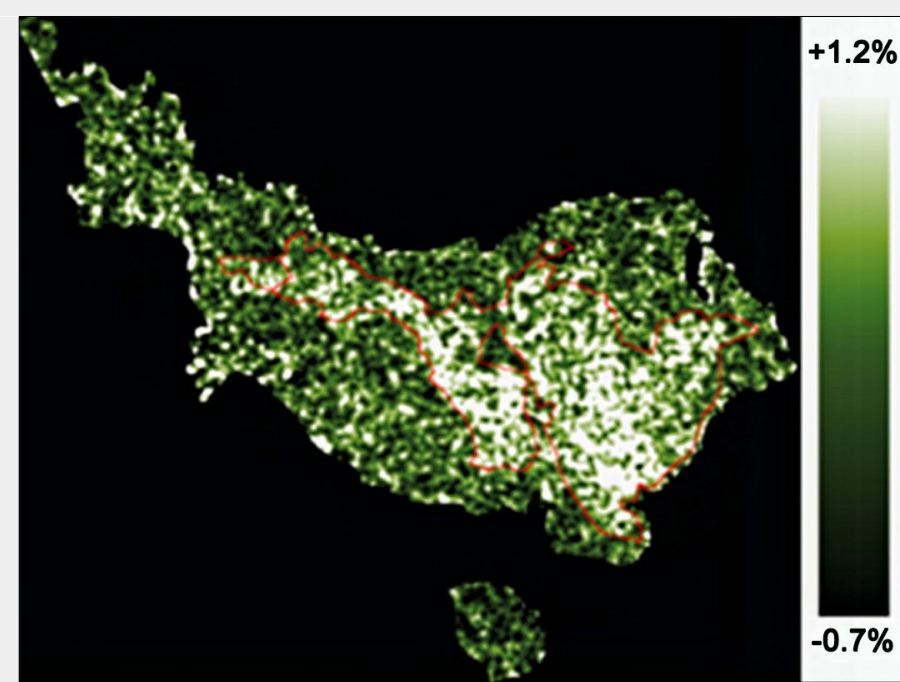

Fig. 5 - $\mathrm{HV} / \mathrm{HH}$ growth rates calculated over Capo Figari area. In red the burnt area perimeter according to field GPS measures. 
for low-biomass forests.

Different researches highlighted the usefulness of optical and SAR data for burnt area detection, also used in conjunction in the Mediterranean region (Stroppiana et al. 2015). Although optical data have been more frequently used, recent studies have been also conducted with different SAR data types, as shown by the Gitas et al. (2012) review. As an example, free Sentinel 1 data have been used to detect burnt areas and estimate related carbon emissions at country level in Indonesia (Lohberger et al. 2017). At local level, in South Africa, RADARSAT-2 and Sentinel 1 C-band SAR polarimetric data showed the capability to detect burnt areas, with results similar to those obtained with Sentinel 2 data (Engelbrecht et al. 2017). Our results show that also CSK, which according to our knowledge has not previously tested for monitoring of burnt areas and regrowth, can be exploited for this purpose. SAR insensitiveness to clouds and haze represents an advantage with respect to optical data use, with the high temporal resolution of CSK constituting an especially relevant feature that allows rapid response in hazard emergency. The presented results are in line with the indications provided by Imperatore et al. (2017), suggesting the use of SAR in Sardinia island for fire scar detection.

The varied topography in the study area allowed to study the SAR response at difference incidence angles, which is a useful information when data acquisition campaigns have to be planned. The results from both $\mathrm{BCl}$ and $\triangle \mathrm{NBR}$ indices were slightly higher in areas characterized by lower incidence angles. In the two Sparse Vegetation sub-areas (AR1, AR2) the indices tended to show lower values, in accordance with the low vegetation density presence. The higher correlation between optical and SAR-based indices was obtained in the Dense Maquis sub-area, indicating a similar response to vegetation foliar changes.

Exploring the different polarizations of CSK data revealed that the polarization ratio is more sensitive to changes in vegetation volume, due to volumetric scattering contribution to the signal, with evident differences between burnt and unburnt maquis. It was recognized that $X$-band shows a smaller dynamic range in burnt severity compared to longer wavelengths, mainly due to the highest sensitivity to soil roughness and penetration capability (Tanase et al. 2010a, 2011). Usually, when spatial filtering is applied, the effect of incoherent scattering coming from highly rough surfaces can be reduced, but at the expenses of spatial resolution which has to be degraded. In this research the availability of a dense time-series allowed to perform a temporal data processing, limiting the need for filtering and preserving the high spatial resolution which is needed to meet the legislative requirements for burnt area detection (Corona et al. 2008).

The very preliminary results obtained by monitoring the vegetation regrowth indicate that CSK can be useful for this purpose, though additional data are needed to support this initial evidence. The monitoring of vegetation regrowth can be important for post-fire planning interventions, especially in regions affected by repeated drought events. It is expected that combining two different frequencies, e.g., CSK and the freely available Sentinel data, can further support vegetation monitoring even at more advanced stage of regrowth, and at fine scales, as previously shown by Holecz et al. (2010). Forest regeneration it is important for carbon cycling, but its monitoring is considered difficult, with previous efforts primarily based on optical data (Bolton et al. 2017). Recently, L-band SAR data have been successfully employed to monitor regeneration under different restoration treatment in China (Chen et al. 2018). The use of SAR data for monitoring vegetation regrowth is also supported by the indication that the optical signature from burnt area deteriorates rapidly, resulting in fire-disturbed sites begin poorly distinguishable from unburned sites by the end of the post-fire season (Jenkins et al. 2014). Overall, considering the positive results obtained also in comparison with optical data, and the broad image availability in allweather conditions, the present study promotes a wider adoption of SAR data for vegetation fire monitoring, at least for short and mid-term assessment stages.

\section{Acknowledgements}

We thank the Sardinian Forest Service (Corpo Forestale e di Vigilanza AmbientaleServizio territoriale dell'sspettorato dipartimentale di Tempio) for the valuable information and assistance provided during our field visits and sampling.

GVL and DP thank the EU for supporting the $\mathrm{BACl}$ project funded by the EU's Horizon 2020 Research and Innovation Program under grant agreement 640176 .

\section{References}

Arnett JT, Coops NC, Daniels LD, Falls RW (2015). Detecting forest damage after a low-severity fire using remote sensing at multiple scales. International Journal of Applied Earth Observation and Geoinformation 35: 239-246. - doi: 10.1016/j.jag.2014.09.013

Attema E, Ulaby FT (1978). Vegetation modeled as a water cloud. Radio science 13 (2): 357-364. doi: 10.1029/RS013i002po0357

Bastos A, Gouveia C, Da Camara C, Trigo R (2011). Modelling post-fire vegetation recovery in Portugal. Biogeosciences 8 (12): 3593-3607. - doi: 10.5194/bg-8-3593-2011

Bernhard EM, Twele A, Gähler M (2011). Rapid mapping of forest fires in the European Mediterranean region-a change detection approach using X-band SAR-data. Photogrammetrie-Fernerkundung-Geoinformation 4: 261-270. - doi: 10.1127/1432-8364/2011/0087

Bernhard EM, Twele A, Gahler M (2012). Burnt area mapping in the European-Mediterranean: SAR backscatter change analysis and synergistic use of optical and SAR data. In: Proceedings of Geoscience and Remote Sensing Symposium (IGARSS) 22-27 July 2012. IEEE International, Munich, Germany, pp. 2141-2143. - doi: 10.1109/ IGARSS.2012.6351080

Bolton DK, Coops NC, Hermosilla T, Wulder MA, White JC (2017). Assessing variability in postfire forest structure along gradients of productivity in the Canadian boreal using multi-source remote sensing. Journal of Biogeography 44 (6): 1294-1305. - doi: 10.1111/jbi.12947

Chen W, Jiang H, Moriya K, Sakai T, Cao C (2018). Monitoring of post-fire forest regeneration under different restoration treatments based on ALOS/PALSAR data. New Forests 49 (1): 105121. - doi: 10.1007/s11056-017-9608-2

Chu T, Guo X, Takeda K (2016). Remote sensing approach to detect post-fire vegetation regrowth in Siberian boreal larch forest. Ecological Indicators 62: 32-46. - doi: 10.1016/j.ecolind. 2015.11.026

Cocke AE, Fulé PZ, Crouse JE (2005). Comparison of burn severity assessments using differenced normalized burn ratio and ground data. International Journal of Wildland Fire 14 (2): 189-198. - doi: 10.1071/WF04010

Corona P, Lamonaca A, Chirici G (2008). Remote sensing support for post fire forest management. iForest - Biogeosciences and Forestry 1 (1): 6-12. - doi: 10.3832/ifor0305-0010006 Covello F, Battazza F, Coletta A, Lopinto E, Fiorentino $C$, Pietranera $L$, Valentini $G$, Zoffoli S (2010). Cosmo-SkyMed an existing opportunity for observing the earth. Journal of Geodynamics 49 (3): 171-180. - doi: 10.1016/j.jog.2010.01.001 Diaz-Delgado R, Pons X (2001). Spatial patterns of forest fires in Catalonia (NE of Spain) along the period 1975-1995: analysis of vegetation recovery after fire. Forest Ecology and Management 147 1: 67-74. - doi: 10.1016/So378-1127(00) 00434-5

Diaz-Delgado R, Lloret F, Pons X (2003). Influence of fire severity on plant regeneration by means of remote sensing imagery. International Journal of Remote Sensing 24 (8): 17511763. - doi: 10.1080/01431160210144732 Engelbrecht J, Theron A, Vhengani L, Kemp J (2017). A simple normalized difference approach to burnt area mapping using multi-polarisation C-Band SAR. Remote Sensing 9 (8): 764. - doi: 10.3390/rs9080764

Gimeno M, San-Miguel-Ayanz J (2004). Evaluation of Radarsat-1 data for identification of burnt areas in southern Europe. Remote Sensing of Environment 92 (3): 370-375. - doi: 10.1016/j.rse.2004.03.018

Gitas I, Mitri G, Veraverbeke S, Polychronaki A (2012). Advances in remote sensing of post-fire vegetation recovery monitoring - a review. In: "Remote Sensing of Biomass - Principles and Applications" (Fatoyinbo L ed). InTech, London, UK, 143-177. - doi: 10.5772/20571

Holecz F, Barbieri M, Eyre C, Mönnig N (2010). Forest management-mapping, monitoring, and inference of biophysical parameters using ALOS PALSAR and Cosmo-SkyMed data. JAXA Kyoto and Carbon Initiative 2010, Tokyo, Japan, pp. 10. [online] URL: http://pdfs.semanticschol ar.org/afee/25481acac37dfbecc49138851d170ca 
2c529.pdf

Imperatore P, Azar R, Calo F, Stroppiana D, Brivio PA, Lanari R, Pepe A (2017). Effect of the vegetation fire on backscattering: an investigation based on Sentinel-1 observations. IEEE Journal of Selected Topics in Applied Earth Observations and Remote Sensing 10 (10): 4478-4492. - doi: 10.1109/JSTARS.2017.2717039 Jenkins LK, Bourgeau-Chavez LL, French NH, Loboda TV, Thelen BJ (2014). Development of methods for detection and monitoring of fire disturbance in the Alaskan tundra using a twodecade long record of synthetic aperture radar satellite images. Remote Sensing 6 (7): 63476364. - doi: 10.3390/rs6076347

Joyce KE, Belliss SE, Samsonov SV, McNeill SJ, Glassey PJ (2009). A review of the status of satellite remote sensing and image processing techniques for mapping natural hazards and disasters. Progress in Physical Geography 33 (2): 183-207. - doi: 10.1177/0309133309339563 Karteris M (1996). Burned land mapping and post-fire effects. EARSeL eProceedings 4: 9096. [online] URL: http://m.eproceedings.org/Ad vances/4-4-1996/4-4_11_Karteris.pdf

Kasischke E, Hoy E, French N, Turetsky M (2007). Post-fire evaluation of the effects of fire on the environment using remotely-sensed data. In: " 6 $^{\text {th }}$ EARSeL Towards an Operational Use of Remote Sensing in Forest Fire Management". Thessaloniki (Greece) 27-29 Sept 2007. Office for Official Publications, European Community, Luxembourg, pp. 38-56.[online] URL: http:// www.researchgate.net/publication/262004437

Key C, Benson N (2004). Ground measure of severity, the composite burn index. Firemon Landscape Assessment 4: 1-55.

Kurum M (2015). C-band SAR backscatter evaluation of 2008 Gallipoli forest fire. IEEE Geoscience and Remote Sensing Letters 12 (5): 10911095. - doi: 10.1109/LGRS.2014.2382716

Lentile LB, Holden ZA, Smith AM, Falkowski MJ, Hudak AT, Morgan P, Lewis SA, Gessler PE, Benson NC (2006). Remote sensing techniques to assess active fire characteristics and postfire effects. International Journal of Wildland Fire 15 (3): 319-345. - doi: 10.1071/WF05097

Lohberger S, Stängel M, Atwood EC, Siegert F (2017). Spatial evaluation of Indonesia's 2015 fire affected area and estimated carbon emissions using Sentinel-1. Global Change Biology 24 (2): 644-654. - doi: 10.1111/gcb.13841

Mari N, Laneve G, Cadau E, Porcasi X (2012). Fire damage assessment in Sardinia: the use of Alos /Palsar data for post fire effects management. European Journal of Remote Sensing 45 (1): 233-241. - doi: 10.5721/EuJRS20124521

Miller JD, Knapp EE, Key CH, Skinner CN, Isbell
CJ, Creasy RM, Sherlock JW (2009). Calibration and validation of the relative differenced normalized burn ratio (RDNBR) to three measures of fire severity in the Sierra Nevada and Klamath mountains, California, USA. Remote Sensing of Environment 113 (3): 645-656. - doi: 10.1016/j.rse.2008.11.009

Minchella A, Del Frate F, Capogna F, Anselmi S, Manes F (2009). Use of multitemporal sar data for monitoring vegetation recovery of Mediterranean burned areas. Remote Sensing of Environment 113 (3): 588-597. - doi: 10.1016/j.rse. 2008.11.004

Polychronaki A, Gitas IZ, Veraverbeke S, Debien A (2013). Evaluation of Alos Palsar imagery for burned area mapping in Greece using objectbased classification. Remote Sensing 5 (11): 5680-5701. - doi: 10.3390/rs5115680

Ranson K, Sun G, Kovacs K, Kharuk V (2002). Utility of SAR for mapping forest disturbance in Siberia. In: Proceedings of the "Geoscience and Remote Sensing Symposium". Toronto (Canada) 24-28 June 2002. IEEE International 4: 20812083.

Richter R, Schläpfer D (2015). Atmospheric/topographic correction for satellite imagery: ATCOR-2/3 user guide, version 9.0.0. Wessling, ReSe Applications Schläpfer, Switzerland, pp. 254.

Ricotta C, Avena G, Olsen E, Ramsey R, Winn D (1998). Monitoring the landscape stability of Mediterranean vegetation relation to fire with a fractal algorithm. International Journal of Remote Sensing 19 (5): 871-881. - doi: 10.1080/014 311698215766

Ruffault J, Mouillot F (2017). Contribution of human and biophysical factors to the spatial distribution of forest fire ignitions and large wildfires in a French Mediterranean region. International Journal of Wildland Fire 26 (6): 498-508. doi: 10.1071/WF16181

Saatchi S, Halligan K, Despain DG, Crabtree RL (2007). Estimation of forest fuel load from radar remote sensing. IEEE Transactions on Geoscience and Remote Sensing 45 (6): 1726-1740. doi: 10.1109/TGRS.2006.887002

San-Miguel-Ayanz J, Schulte E, Schmuck G, Camia A, Strobl P, Liberta G, Giovando C, Boca R, Sedano F, Kempeneers P, Mcinerney D, Withmore C, De Oliveira SS, Rodrigues M, Durrant T, Corti P, Oehler F, Vilar L, Amatulli G (2012). Comprehensive monitoring of wildfires in Europe: the European Forest Fire Information System (EFFIS). In: “Approaches to Managing Disaster - Assessing Hazards, Emergencies and Disaster Impacts". InTech, London, UK, pp. 87108. - doi: $10.5772 / 28441$

Shoshany M (2000). Satellite remote sensing of natural Mediterranean vegetation: a review within an ecological context. Progress in Physical Geography 24 (2): 153-178. - doi: 10.1177/0309 13330002400201

Stroppiana D, Azar R, Calò F, Pepe A, Imperatore P, Boschetti M, Silva J, Brivio P, Lanari R (2015). Integration of optical and SAR data for burned area mapping in Mediterranean regions. Remote Sensing 7 (2): 1320-1345. - doi: 10.3390/rs 70201320

Tanase MA, Santoro M, De La Riva J, PerezCabello F, Le Toan T (2010a). Sensitivity of X-, C-, and I-band SAR backscatter to burn severity in Mediterranean pine forests. IEEE Transactions on Geoscience and Remote Sensing 48 (10): 3663-3675. - doi: 10.1109/TGRS.2010.20496 53

Tanase MA, Perez-Cabello F, De La Riva J, Santoro M (2010b). TerraSAR-X data for burn severity evaluation in Mediterranean forests on sloped terrain. IEEE Transactions on Geoscience and Remote Sensing 48 (2): 917-929. - doi: 10.1109/TGRS.2009.2025943

Tanase MA, Santoro M, Wegmuller De La Riva J, Perez-Cabello F (2010C). Properties of X-, C- and I-band repeat-pass interferometric SAR coherence in Mediterranean pine forests affected by fires. Remote Sensing of Environment 114 (10): 2182-2194. - doi: 10.1016/j.rse.2010.04.021

Tanase MA, De La Riva J, Santoro M, Perez-Cabello F, Kasischke E (2011). Sensitivity of sar data to post-fire forest regrowth in Mediterranean and boreal forests. Remote Sensing of Environment 115 (8): 2075-2085. - doi: 10.1016/j. rse.2011.04.009

Tanase MA, Santoro M, Aponte C, De La Riva J (2014). Polarimetric properties of burned forest areas at c- and I-band. IEEE Journal of Selected Topics in Applied Earth Observations and Remote Sensing 7: 267-276. - doi: 10.1109/JSTARS. 2013.2261053

Tanase MA, Kennedy R, Aponte C (2015). Fire severity estimation from space: a comparison of active and passive sensors and their synergy for different forest types. International Journal of Wildland Fire 24 (8): 1062-1075. - doi: 10.1071/ WF15059

Ulander L (1996). Radiometric slope correction of synthetic-aperture radar images. IEEE Transactions on Geoscience and Remote Sensing 34: 1115-1122. - doi: 10.1109/36.536527

Van Wagtendonk JW, Root RR, Key CH (2004). Comparison of Aviris and Landsat ETM+ detection capabilities for burn severity. Remote Sensing of Environment 92 (3): 397-408. - doi: 10.1016/j.rse.2003.12.015 